\title{
Formation of tabular plutons - results and implications of centrifuge modelling
}

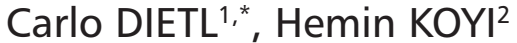

${ }^{1}$ Institut für Geowissenschaften, Goethe-Universität, Altenhöferallee 1, D-60438 Frankfurt am Main, Germany; c.dietl@em.uni-frankfurt.de

${ }^{2}$ Hans Ramberg Tectonic Laboratory, Department of Earth Sciences, Uppsala University, Villavägen 16, S-75236 Uppsala, Sweden

* Corresponding author

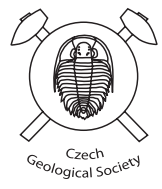

Geophysical investigations reveal that many granitoid plutons possess a tabular shape: either laccolithic, lopolithic or phacolithic. In this study, the results of a centrifuge experiment are used to understand the formation mechanisms of these features. The model was build of a sequence of 14 differently coloured plasticine layers. Two buoyant layers - with a volume of $c .40 \mathrm{~cm}^{3}$ each - were incorporated into the model stratigraphy at different depths to investigate, whether the rise and emplacement of buoyant material at different levels results in different intrusion structures.

After centrifuging for $30 \mathrm{~min}$ at $700 \mathrm{G}$, both the buoyant layers had formed two lenticular sills (phacoliths) with aspect ratios (length/thickness) of 6 and 3.4 for the upper and lower phacoliths, respectively, directly above both pre-existing perturbations in the buoyant layers. During their movement, the buoyant phacoliths had pushed their roof plasticine upward. Simultaneously, their floor plasticine had subsided (bottom sinking). Subsidence of the floor material had choked the inflow of further buoyant material into the feeder channel of the developing sills and inhibited their further lateral growth.

The observed forced downward movement of the plasticine floor of the forming PDMS (polydimethylsiloxane) phacoliths resembles the so-called "floor depression" of host rock material around an emplacing tabular pluton. Floor depression is supposed to be a very important vertical material transfer process, which provides space for the construction of lopoand phacoliths. The subsidence of host material made space for the developing buoyant phacoliths, but also restricted their growth to a certain time slot before the influx of new buoyant material into the feeder dyke of the tabular intrusive body was shut off. Similarly, in nature, the growth of a tabular pluton might be limited not only by the rate of magma ascent and its physical properties, but also by the emplacement processes of the evolving pluton.

Keywords: phacoliths, laccoliths, tabular plutons, ascent, emplacement, centrifuge modelling

Received: 16 September 2008; accepted 17 December 2008; handling editor: J. Žák

\section{Introduction}

Field geological as well as geophysical investigations on numerous large plutons (encompassing areas in the range of several hundred up to more than thousand $\mathrm{km}^{2}$ ) during the last 20 years have revealed that many of them are of tabular, either laccolithic (convex roof and straight floor) or lopolithic (straight roof and concave floor) or phacolithic (biconvex) shape. Despite their differences in emplacement level and tectonic setting, the development of the lensoidal shapes of all these plutons can be described as a three-stage process (e.g. Corry 1988; Cruden 1998). In a first stage a vertical dyke is established, where magma is transported upward until it reaches a horizontal unconformity along which the magma then - in the second stage - spreads laterally to form a sill. In the third stage additional magma ascends through the feeder dyke to be emplaced into the sill, which inflates due to the magma overpressure by doming of the roof and/or depression of the floor of the growing pluton. These three stages are incremental processes and intimately entangled with each other, in particular in the case of composite plutons which consist of several magma batches. Magma ascent generated by dyking as well as roof uplift and floor depression of the developing pluton take advantage of shear zones and faults; either as magma pathways (magma ascent) or as planes of movement along which individual blocks of the roof and floor of the evolving pluton are shifted upward or downward (magma emplacement). The lateral spreading of magma prior to magma chamber inflation benefits from horizontal anisotropy planes in the host rock, such as bedding and foliation planes, fractures or shear zones. According to Cruden (1998) the roof uplift plays a major role as a space-making process only for laccoliths emplaced in the uppermost crust at around $3 \mathrm{~km}$ depth, while floor depression seems to be responsible for most of the - then lopolithic - tabular plutons being emplaced deeper within the Earth's crust below c. 4-5 km depth.

Based on dimensional data from several hundred plutons McCaffrey and Petford (1997) and Petford and Clemens (2000) showed that the proportions of intrusive 
bodies (length vs. thickness) can be described by the following power law:

$$
T=c \times L^{a}
$$

with pluton thickness $T$, its length $L$, a constant $c$ and the power-law exponent $a$.

McCaffrey and Petford (1997) based their calculations on field data from 135 laccoliths and 21 plutonic intrusions. According to their data base power law (1.1) for laccoliths only can be formulated as:

$$
T=0.12 \times L^{0.88}
$$

while power law (1.1) applied to plutons is

$$
T=0.29 \times L^{0.80}
$$

Cruden (1998) ended up with a value of 0.29 for constant $c$ when calculating the power law relationship between the length and thickness of tabular plutons. Petford and Clemens (2000) found - based on the dimensional data from more than 100 plutons and batholiths - that the power law exponent $a$ in formula (1.1) equals $0.6 \pm 0.1$. According to Petford et al. (2000), tabular plutons, which are established mainly by downward directed material transfer (e.g. floor depression) can be distinguished from laccoliths from the power-law regression lines they follow in a $\log _{\text {length }}$ vs. $\log _{\text {thickness }}$ plot. Laccoliths plot along a power-law regression line with $a=0.88 \pm 0.1$, while plutons appear in this diagram along regression line with $a=0.60 \pm 0.1$ (Fig. 1).

The differences in numbers for $a$ and $c$ reflect the differing data sets the individual power law formulas

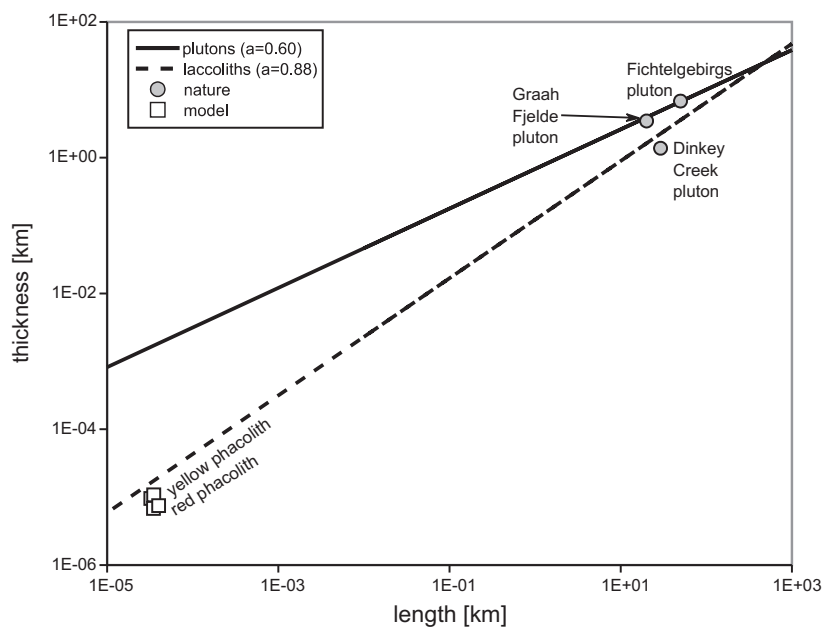

Fig. 1 Length vs. thickness plot for plutons and laccoliths, showing their differing dimensional ratios as expressed by the two regression lines (Petford et al. 2000). Grey dots indicate length-thickness ratios of the three real plutons discussed in text, open squares show the dimensions of the model phacoliths.

are based on and the quality of these data. Moreover, for the formulation of the individual equations only two - thickness and length - of the three available dimensional data (thickness, length and width) are taken into account. However, in particular the thickness data for the individual intrusions are not well constrained, because until today no major intrusive body with exposed roof and floor was observed. In particular descriptions of outcropping intrusion floors lack almost entirely in literature. One exception is the Bergell pluton in the Central Alps, the floor of which is exposed, together with its root zone (Rosenberg et al. 1995). Consequently, information about

\section{Dinkey Creek pluton (Sierra Nevada, California)}

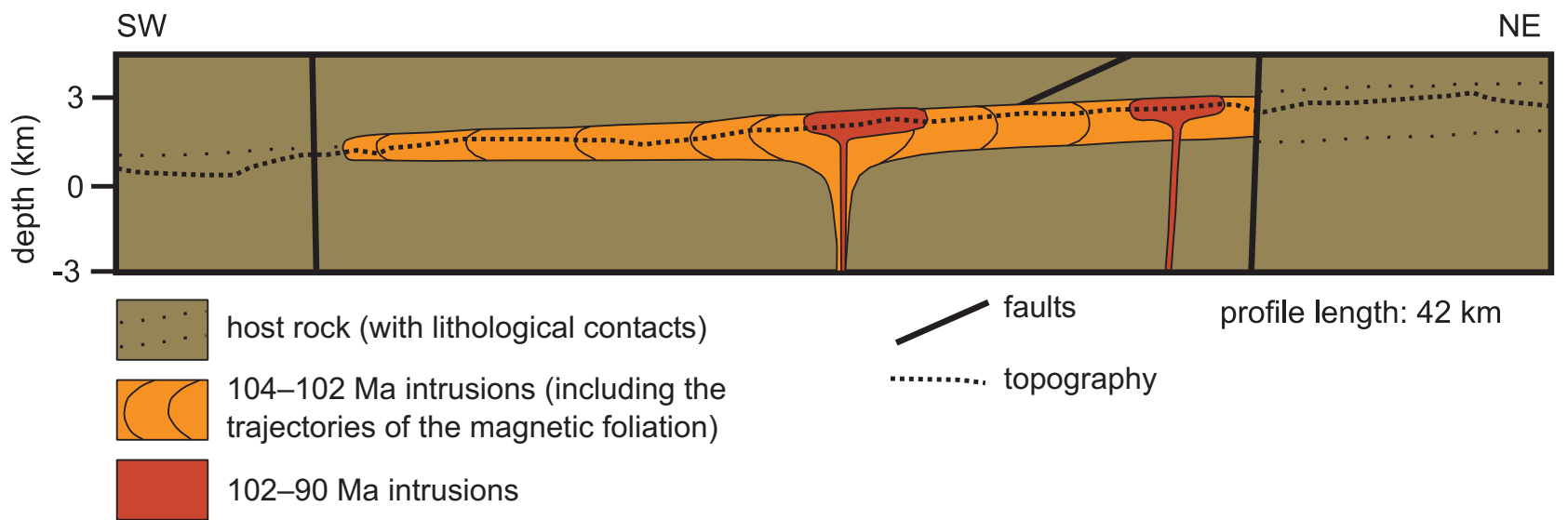

Fig. 2 Cross section through the Cretaceous Dinkey Creek pluton (Sierra Nevada, redrawn from Cruden et al. 1999). 
intrusion floors stem mainly from indirect, geophysical methods, such as gravimetry and seismic investigations. Nevertheless, all these six power laws for laccoliths and plutons have one thing in common: the power law exponent $a$ is always $<1$, indicating the tabular shape of the granitoid bodies. However, the power law behaviour of these tabular intrusives does not only describe their shape, but also their growth: they start as thin, horizontal sills, which only after some lateral growth expand also vertically, giving them their final tabular shape.

\section{Natural examples for tabular plutons}

Typical tabular plutons include the upper-crustal, synorogenic Cretaceous Dinkey Creek pluton in the Sierra Nevada (California; Cruden et al. 1999; Hammarstrom and Zen 1986; Fig. 2), the mid-crustal, late-orogenic Carboniferous Fichtelgebirge pluton (Bohemian Massif; Hecht and Vigneresse 1999; O’Brien 2000; Fig. 3), and the upper-crustal, late- to post-orogenic Proterozoic Graah Fjelde Rapakivi Granite (Greenland - Grocott et

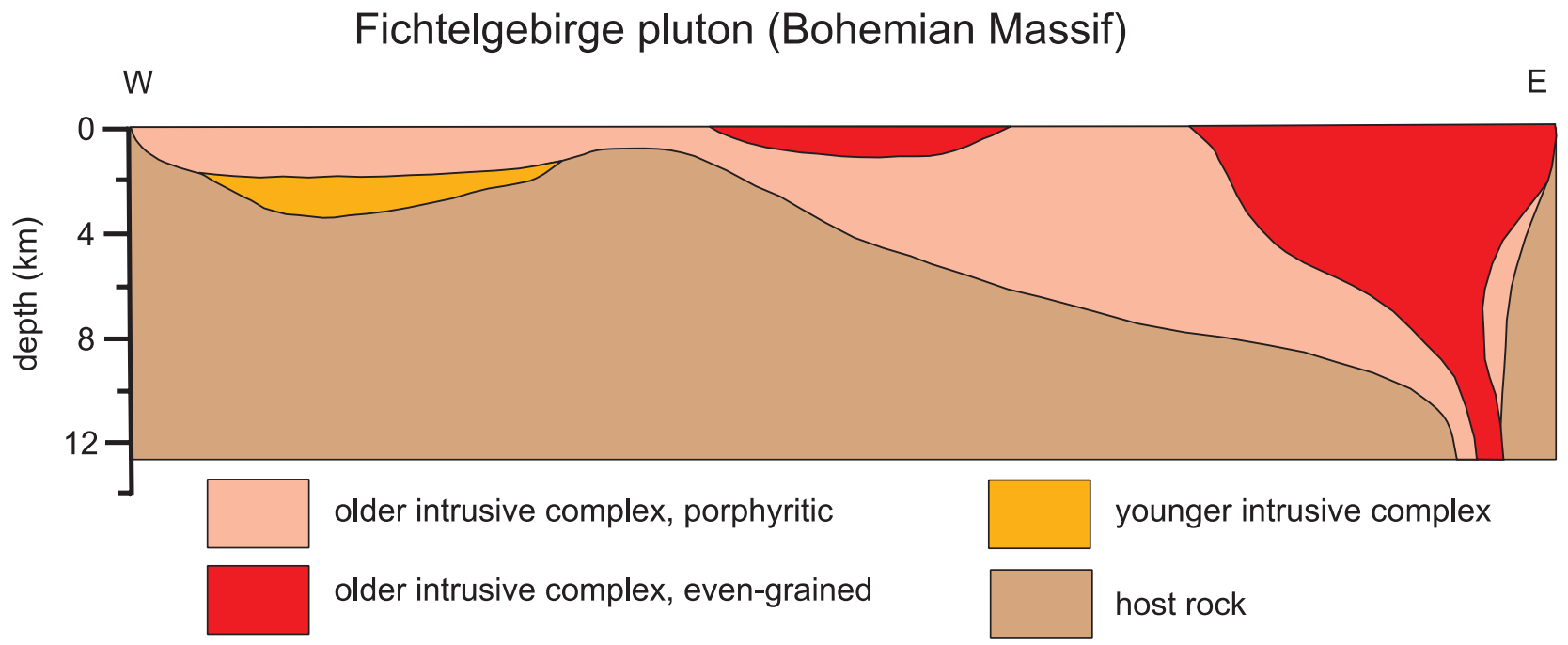

profile length: $50 \mathrm{~km}$

Fig. 3 Cross section through the Variscan Fichtelgebirge pluton (Bohemian Massif, redrawn from Hecht and Vigneresse 1999). The older and younger intrusive complexes are genetically not related to each other (J.L. Vigneresse, pers. comm.).

\section{Graah Fjelde rapakivi granite complex, (E. Greenland)}

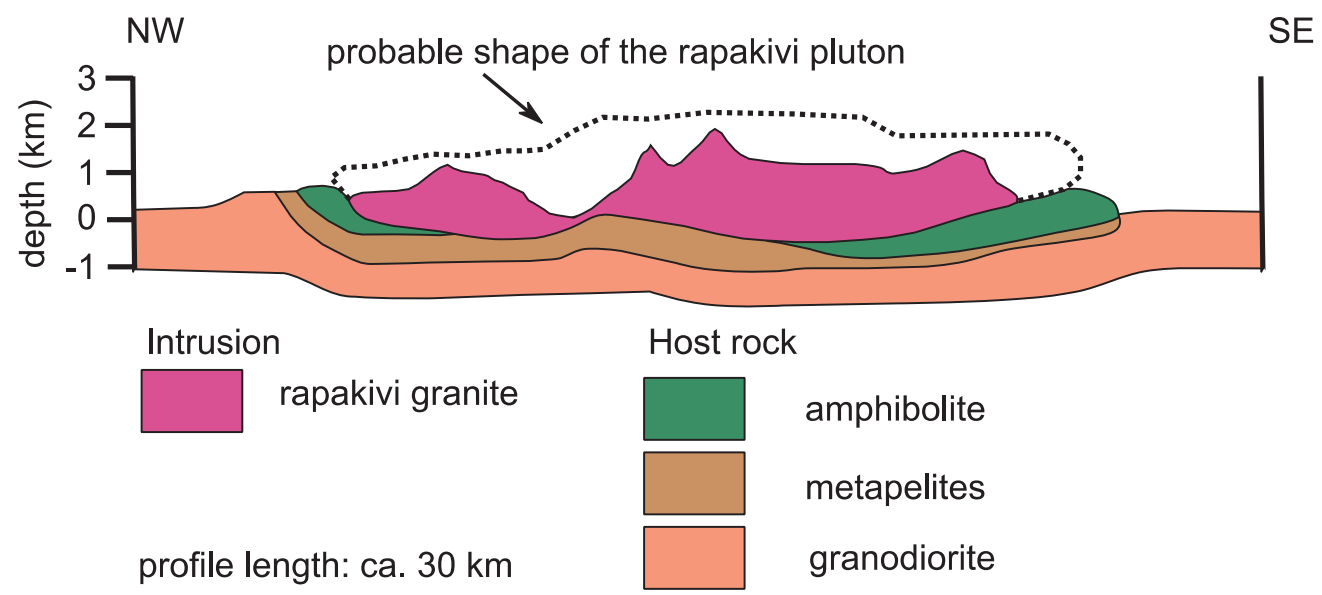

Fig. 4 Cross section through the Precambrian Graah Fjelde Rapakivi Granite (Greenland, redrawn from Garde et al. 2002). 
al. 1999; Garde et al. 2002; Fig. 4). Grocott et al. (1999), Hecht and Vigneresse (1999) and Cruden et al. (1999) suggested floor depression by the inflowing magma due to its overpressure as the main emplacement mechanism for the Graah Fjelde, Fichtelgebirge and Dinkey Creek plutons, respectively. All three tabular intrusions named here follow the power-law for pluton proportions developed by McCaffrey and Petford (1997) and Petford and Clemens (2000). Plotting the thickness-length ratios of the Graah Fjelde, Fichtelgebirge and Dinkey Creek plutons, respectively (calculated based on the cross sections shown in Figs 2-4; see also Tab. 1) reveals that the Graah Fjelde and Fichtelgebirge plutons occur close to the "pluton" regression line and the Dinkey Creek pluton slightly below the "laccolith" regression line (Fig. 1). According to the interpretation of Petford et al. (2000) the Graah Fjelde and Fichtelgebirge plutons should be regarded as lopoliths emplaced by floor depression; and the Dinkey Creek pluton should then be interpreted as a laccolith emplaced by roof-uplift, although all three intrusive bodies plot quite close to the intersection of both the regression lines.

Tab. 1 Dimensions of the three presented plutons as taken from Figs $2-4$, as well as of the two PDMS intrusions in the centrifuge model.

\begin{tabular}{lcc}
\hline Natural examples & Thickness $[\mathrm{km}]$ & Length $[\mathrm{km}]$ \\
\hline Dinkey Creek pluton & 1.38 & 29.22 \\
Fichtelgebirgs pluton & 6.82 & 50.00 \\
Graah Fjelde pluton & 3.47 & 20.06 \\
\hline PDMS intrusions & Thickness [cm] & Length [cm] \\
\hline Yellow phacolith, section 1 & 0.96 & 3.24 \\
Yellow phacolith, section 2 & 1.08 & 3.50 \\
Red phacolith, section 1 & 0.68 & 3.48 \\
Red phacolith, section 3 & 0.75 & 4.00 \\
\hline
\end{tabular}

\section{The experiment}

\subsection{Motivation of the experiment}

The three examples presented briefly above are only a small selection of tabular plutons, which are common features of the continental crust. They develop independently of their temporal, tectonic or rheological context, usually according to the same ascent and emplacement style, i.e. dyking, followed by sill formation and magma chamber inflation. According to McCaffrey and Petford (1997), their growth during emplacement is ruled by the power law (1.1). Consequently, also the dimensions of a growing pluton follow the power law (1.1): it lengthens more rapidly than it thickens.

Analogue modeling has proven to be an effective tool in studying geologic structures and processes (Koyi 1997). Here we present the results of an analogue cen- trifuge experiment, to test the viability of the proposed emplacement mechanisms for tabular plutons, in particular:

- how roof uplift and floor depression are linked to each other;

- whether floor depression is more typical of deep-seated and roof uplift more common of shallowly intruding tabular plutons;

- whether floor depression might hinder the filling and inflation of the magma chamber due to chocking of the magma source (provided the magma source is a horizontal layer of partially molten rock).

Moreover, we test the validity of the assumptions made by Petford et al. (2000) concerning the discrimination between (lopolithic) plutons and laccoliths based on power-law regression lines in length-thickness diagrams for intrusive bodies.

\subsection{Setup of the experiment}

The overall shape of the model was cylindrical with a diameter of $10 \mathrm{~cm}$ and $6.75 \mathrm{~cm}$ thick. The scaling factor for distances is $10^{-5}$ (length $_{\text {model }} /$ length ${ }_{\text {nature }}$ ), i.e. $1 \mathrm{~cm}$ in the model corresponds to $1 \mathrm{~km}$ in nature (Tab. 2). As overburden material a semi-brittle plasticine (density $\rho=1.71 \mathrm{~g} / \mathrm{cm}^{3}$, viscosity $\mu=4.2 \times 10^{7} \mathrm{~Pa} \cdot \mathrm{s}$ at a strain rate of $10^{-3} \mathrm{~s}^{-1}$ ) was used, representing upper to middle crustal siliciclastic rocks $\left(\rho \approx 2.6 \mathrm{~g} / \mathrm{cm}^{3}\right.$ and $\mu \approx 10^{21}$ $\mathrm{Pa} \cdot \mathrm{s}$ ). Polydimethylsiloxane (PDMS; $\rho=0.964 \mathrm{~g} / \mathrm{cm}^{3}, \mu$ $=4 \times 10^{4} \mathrm{~Pa} \cdot \mathrm{s}$; Koyi 1991) played the role of the buoyant material, corresponding to a partially molten granitic magma $\left(\rho \approx 1.5 \mathrm{~g} / \mathrm{cm}^{3}, \mu \approx 10^{18} \mathrm{~Pa} \cdot \mathrm{s}\right)$. The assumed crustal viscosity of $10^{21} \mathrm{~Pa} \cdot \mathrm{s}$ is quite low, but falls within the range of presumed viscosity values for crustal rocks of $10^{20}$ to $10^{23} \mathrm{~Pa}$-s (Koyi et al. 1999). These estimated viscosity values for the upper and middle crust are based

Tab. 2 Dimensions and physical parameters of both the model and its natural counterpart as well as their ratios ( $\mathrm{t}=$ thickness, $\rho=$ density, $\mu=$ viscosity).

\begin{tabular}{lccc}
\hline Scaling & Model & Nature & $\begin{array}{c}\text { Ratio } \\
\text { (model/ } \\
\text { nature) }\end{array}$ \\
\hline $\begin{array}{l}\mathrm{t}_{\text {overburden }} \\
\text { (red PDMS source layer) }\end{array}$ & $3.2 \mathrm{~cm}$ & $3.2 \mathrm{~km}$ & $10^{-5}$ \\
$\mathrm{t}_{\text {overburden }}$ & & & \\
$\begin{array}{l}\text { (yellow PDMS source layer) } \\
\mathrm{t}_{\text {buoyant }}\end{array}$ & $6.05 \mathrm{~cm}$ & $6.05 \mathrm{~km}$ & $10^{-5}$ \\
$\rho_{\text {overburden }}$ & $0.5 \mathrm{~cm}$ & $500 \mathrm{~m}$ & $10^{-5}$ \\
$\rho_{\text {buoyant }}$ & $1.71 \mathrm{~g} / \mathrm{cm}^{3}$ & $2.63 \mathrm{~g} / \mathrm{cm}^{3}$ & $6.5 \times 10^{-1}$ \\
$\mu_{\text {overburden }}$ & $0.964 \mathrm{~g} / \mathrm{cm}^{3}$ & $1.48 \mathrm{~g} / \mathrm{cm}^{3}$ & $6.5 \times 10^{-1}$ \\
$\mu_{\text {buoyant }}$ & $4 \times 10^{7} \mathrm{~Pa} \cdot \mathrm{s}$ & $10^{21} \mathrm{~Pa} \cdot \mathrm{s}$ & $4.2 \times 10^{-14}$ \\
$\mathrm{~g}$ & $4 \times 10^{4} \mathrm{~Pa} \cdot \mathrm{s}$ & $10^{18} \mathrm{~Pa} \cdot \mathrm{s}$ & $4.2 \times 10^{-14}$ \\
\hline & $6.87 \times 10^{3} \mathrm{~m} / \mathrm{s}^{2}$ & $9.81 \mathrm{~m} / \mathrm{s}^{2}$ & $7 \times 10^{2}$ \\
\hline
\end{tabular}


on experimental determinations of effective viscosities for dry and wet quartzites at a temperature between 300 ${ }^{\circ} \mathrm{C}$ and $700{ }^{\circ} \mathrm{C}$ and at a geologically relevant strain rate of $10^{-14} \mathrm{~s}^{-1}$ (Weyermars 1997 and references therein), which gave effective viscosities between $10^{21} \mathrm{~Pa} \cdot \mathrm{s}$ (wet and hot quartzite) and $10^{23} \mathrm{~Pa} \cdot \mathrm{s}$ (dry and cold quartzite). On the other hand, the assumed viscosity of the partially molten granitic magma - calculated on the basis of the PDMS viscosity - is much too high compared to experimentally determined viscosity values of granitic magmas, which range between $10^{3}$ and $10^{12} \mathrm{~Pa} \cdot \mathrm{s}$ (Dingwell et al. 2000). However, applying proper scaling and using consequently fluids with very low viscosities, such as water $\left(\mu \approx 10^{-3}\right.$ $\mathrm{Pa} \cdot \mathrm{s})$ or olive oil ( $\left.\mu \approx 10^{-1} \mathrm{~Pa} \cdot \mathrm{s}\right)$ as magma analogues would lead to ascent and emplacement structures which are of unrealistic shape for granitic intrusive bodies (Ramberg 1981). As such, the presented model is only partially scaled to nature. However, the model is a first approximation to nature and focuses on the formation of tabular intrusions and the effects of floor depression and roof uplift on their ascent and emplacement in general.

Model stratigraphy included two buoyant layers of PDMS (5 mm thick each and with a volume of $c .40 \mathrm{~cm}^{3}$ each) at the base and in the middle ( $3 \mathrm{~cm}$ high in the model stratigraphy) of the model. At the upper boundary of each buoyant layer a perturbation $(1 \mathrm{~cm} \times 1 \mathrm{~cm} \times 0.7$ $\mathrm{cm})$ was introduced to trigger the formation of two intrusions. Of course, it is impossible to model with these two single intrusions exactly the incremental growth of a tabular pluton due to the continuous influx of magma. However, the presented model serves as a good proxy for the role roof uplift and floor depression play during the ascent into and the construction of a tabular granitoid body due to the rise of a single magma batch. The perturbation of the lower buoyant layer was placed in the centre of the model (5 $\mathrm{cm}$ from its rim), while the perturbation of the middle buoyant layer was shifted from the model's centre by $2.3 \mathrm{~cm}$ (Fig. 5). Both the perturbations were intended to act as pathways for the ascending buoyant material during centrifuging, in correspondence to the feeder dykes of tabular plutons. The horizontal offset between both the perturbations was designed to prevent the developing intrusive bodies to interact too much with each other. The overburden of both the buoyant layers was stratified consisting of five (above the lower buoyant layer) and eight (above the upper buoyant layer) differently coloured plasticine layers of 0.25 to $0.7 \mathrm{~cm}$ thick (Fig. 5).

\subsection{Run of the experiment}

The model was centrifuged in the small centrifuge of the Hans Ramberg Tectonic Laboratory (Uppsala University, Sweden) for $c$. 5 minutes at $700 \mathrm{G}$ when a small bulge formed on top of the model directly above the perturba-

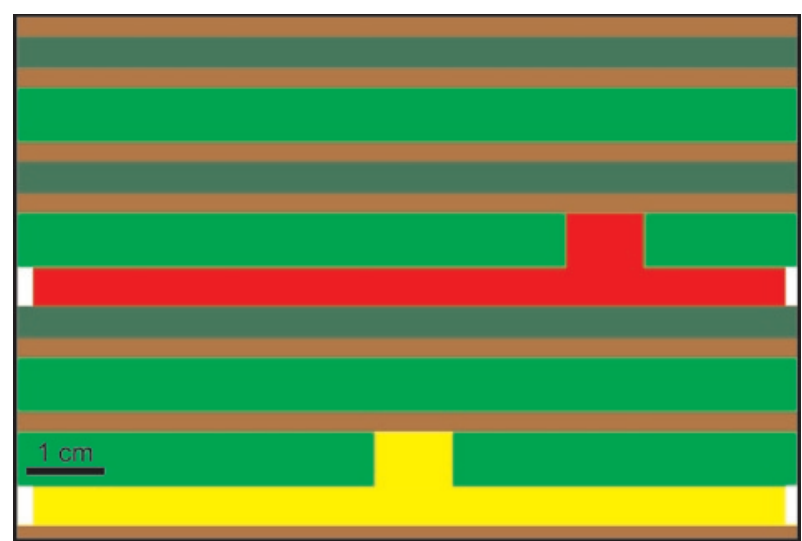

Fig. 5 Setup of the experiment. The yellow and red layers represent the buoyant PDMS, the light and dark green as well brown layers are the plasticine overburden.

tion of the middle buoyant layer. After photographing the top view with the small bulge on the model's surface (Fig. 6), the model was centrifuged for 20 more minutes at $700 \mathrm{G}$ in order to see, whether in the current configuration the bulge on top of the model would increase or a second bulge would form. When no major changes happened after 25 minutes of centrifuging, the uppermost three plasticine layers - in total $0.9 \mathrm{~cm}$ of the overburden - were removed to thin the overburden and assist the rise of the buoyant material. The model was then centrifuged for further 5 minutes at $700 \mathrm{G}$. No major changes in the top view of the model occurred and the model was then sectioned in order to study it in detail.

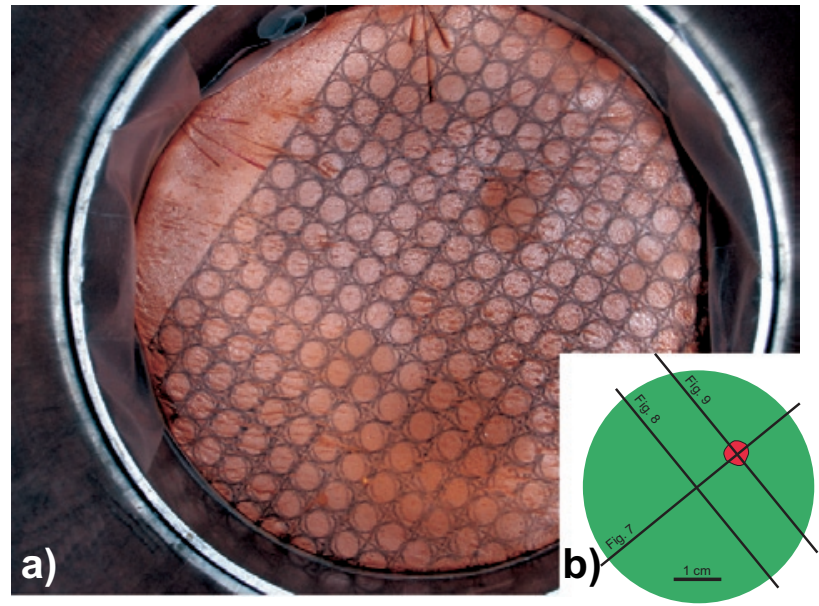

Fig. 6a - Top view of the model after 5 minutes of centrifuging at 700 G. The slight bulge northeast (with north at the top of the image) of the centre marks the location of the upper phacolith. The diameter of the model is $10 \mathrm{~cm}$. Inset $\mathbf{b}$ - sketch of the photograph in Fig. 6a with the location of the red phacolith indicated by the red circular area above and to the right of the centre of the model (model surface in green); the lines indicate the positions of the sections presented in Figs 7-9. 

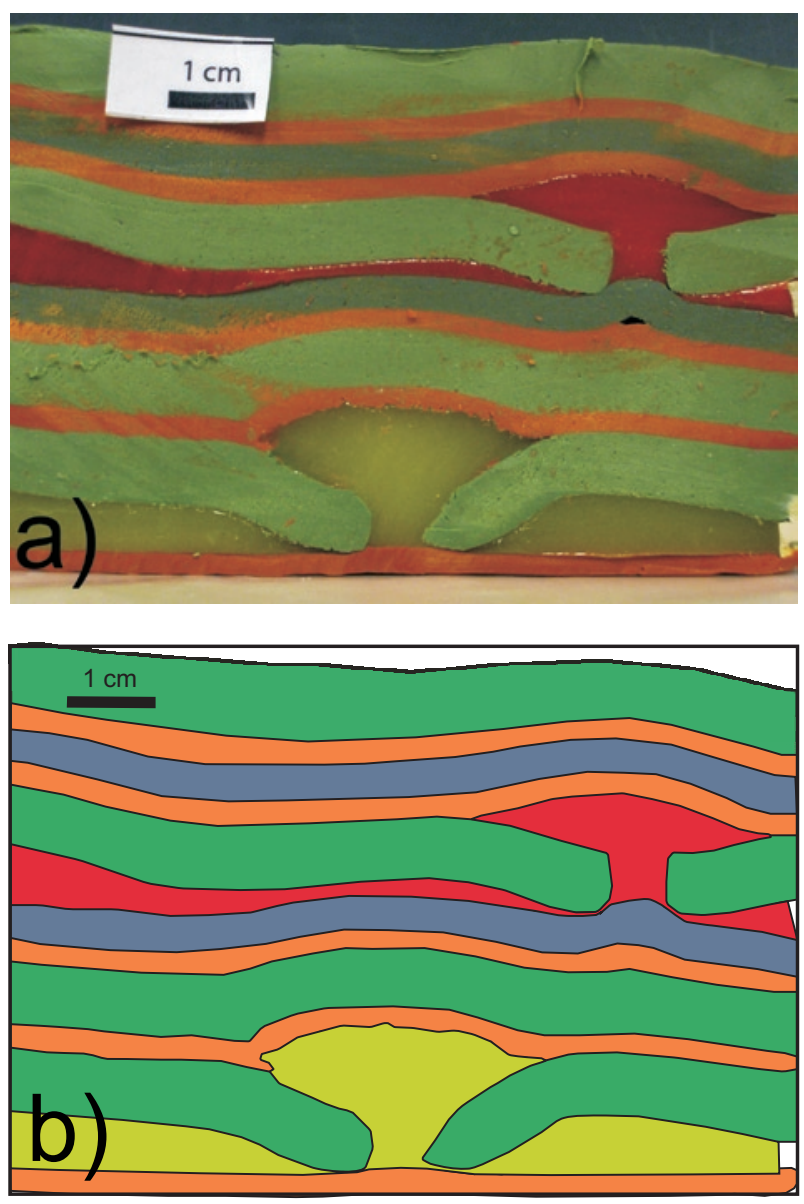

Fig. 7a - Section 1 through the model after 30 minutes of centrifuging at $700 \mathrm{G}$ cutting both phacoliths: the red one in the upper part of the model and the yellow one in its lower part. $\mathbf{b}$ - line drawing of the section shown in Fig. 7a.

\subsection{Results of the experiment}

A first vertical section in the middle of the model showed two tabular intrusive bodies that had formed directly above the perturbations along the interface between the buoyant layers and the overburden layers immediately overlying them (Fig. 7). Both the intrusions are characterized by a domed-up roof and a depressed floor, which is typical of phacoliths. The subsided floors of both PDMS bodies cut off the influx of the buoyant material from the source layers. The overburden units above the lower phacolith bulge into the middle buoyant layer, which accommodates the deformation by thinning (Fig. 7). The plasticine layers initially located directly above the buoyant layers, partly detach from the overlying overburden layers and subside in the immediate vicinity of the perturbations (Fig. 7). Moreover, the plasticine layer immediately beneath the perturbation of the upper buoyant layer is detached from its pad to form a small bulge (Fig. 7).
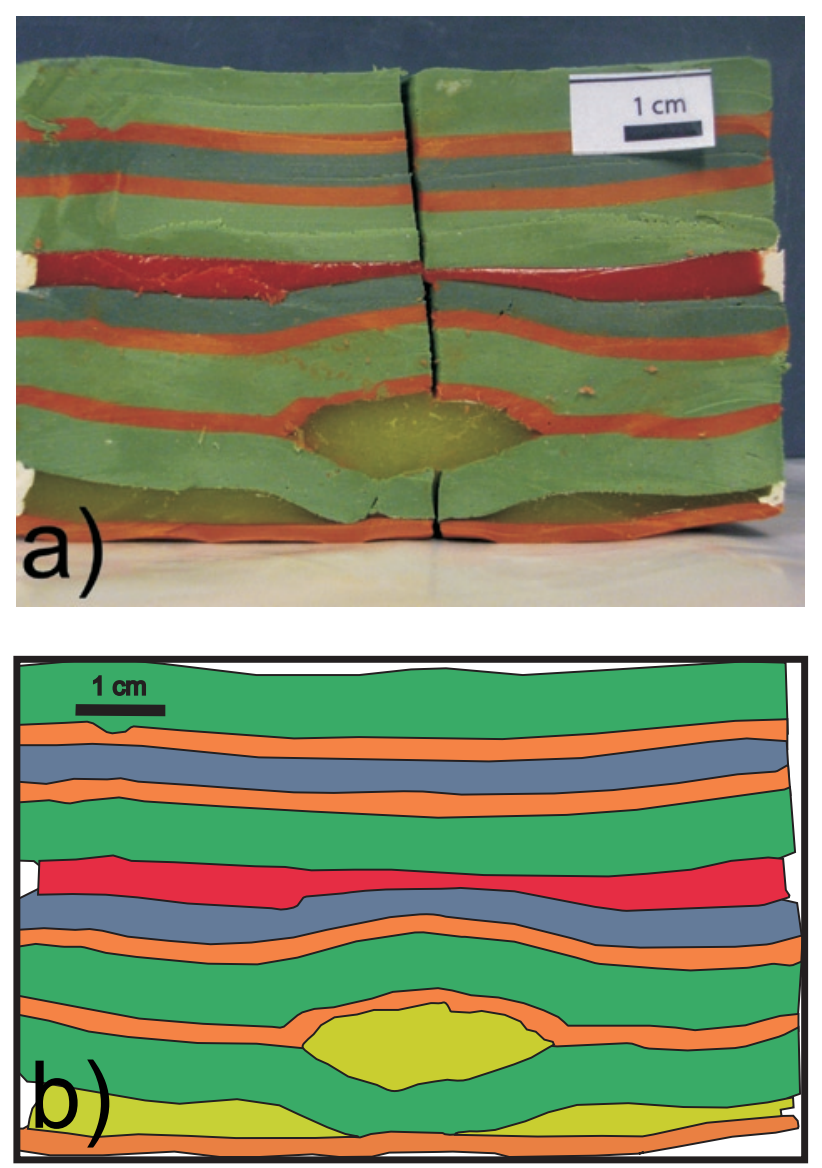

Fig. 8a - Section 2 - perpendicular to section 1 - through the model after 30 minutes of centrifuging at $700 \mathrm{G}$ proofs the lensoidal shape of the yellow intrusive PDMS body. $\mathbf{b}$ - line drawing of the section shown in Fig. 8a.

Two additional profiles (Figs 8 and 9), both perpendicular to the first one and carving each through one of the two buoyant intrusions, verified the phacolith nature of both bodies and helped to measure their dimensions and, in addition, calculate their volumes. The lower phacolith is between 3.24 and $3.5 \mathrm{~cm}$ in diameter, depending on which section is considered. Its maximum thickness lies between 0.96 and $1.08 \mathrm{~cm}$. The upper phacolith is 3.48 to $4.00 \mathrm{~cm}$ long and 0.68 to $0.75 \mathrm{~cm}$ thick (Tab. 1). The volume of the tabular buoyant bodies was calculated according to the following equation (Bronstein and Semendjajew 1987):

$$
V=2 \times(1 / 6) \pi \times h\left(3 a^{2}+h^{2}\right)
$$

where $h$ is half the height and $a$ is half the diameter of the respective phacoliths.

Accordingly, the volume of the lower intrusion is between 4.06 and $5.34 \mathrm{~cm}^{3}$ and the volume of the middle intrusion ranges between 3.29 and $4.77 \mathrm{~cm}^{3}$. 

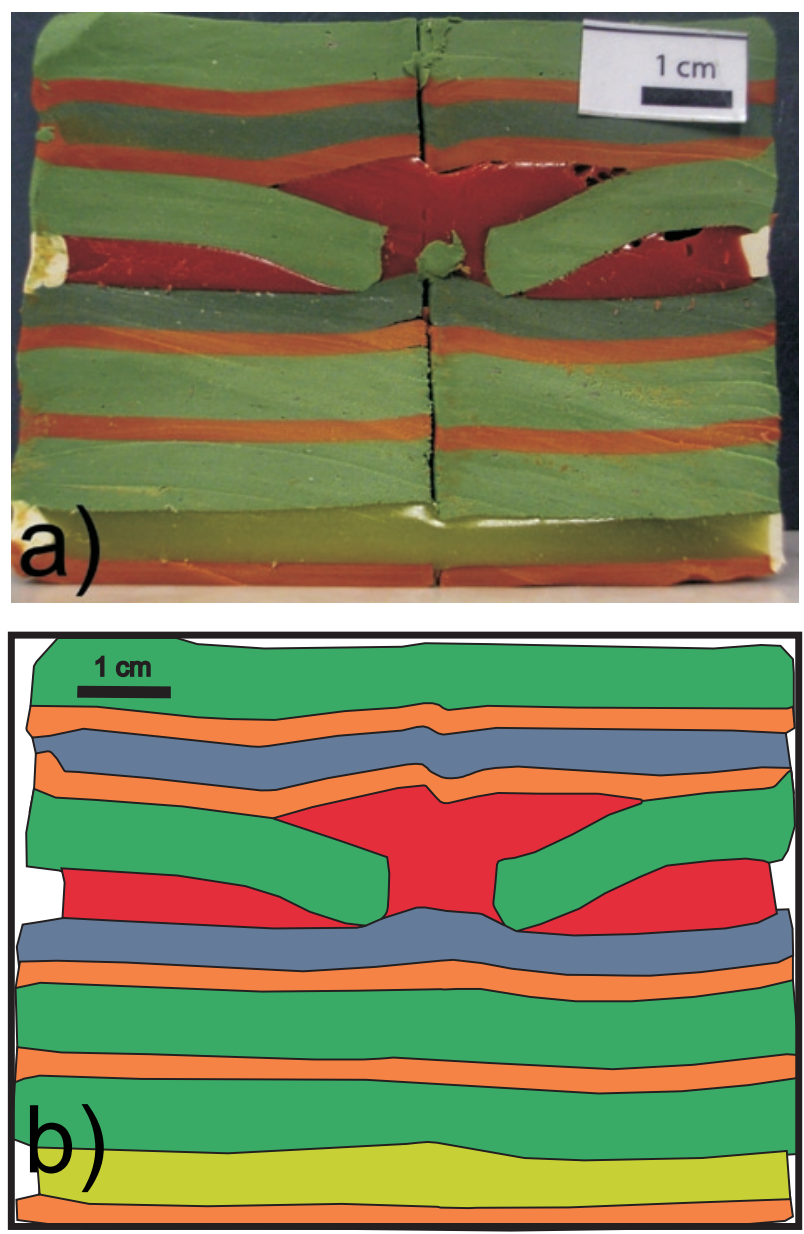

Fig. 9a - Section 3 - perpendicular to section 1 and parallel to section 2 - through the model after 30 minutes of centrifuging at $700 \mathrm{G}$ proofs the lensoidal shape also of the red intrusive PDMS body. $\mathbf{b}$ - line drawing of the section shown in Fig. 9a.

\section{Formation of both the phacoliths}

As planned, the perturbation in the buoyant layers acted as pathways (or feeder dykes) for the buoyant material during centrifuging of the model. However, the buoyant material did not manage to rise through the plasticine overburden and instead spread laterally as sills along the interfaces between the two plasticine layers directly above the buoyant layers. With further centrifuging, additional material was transported buoyantly from the PDMS layer through the feeder dykes into the sills. The influx of new material led to inflation of the sills by vertical displacement of their roofs and floors. Thereby the plasticine above the developing phacoliths was deformed plastically within a distance of 1.5 to $2 \mathrm{~cm}$, while the floors of the inflated intrusions were depressed by $c$. $0.5 \mathrm{~cm}$. Additionally, the thin plasticine layer beneath the upper buoyant layer was sucked up into the conduit of the buoyant body by the upward moving buoyant material. On the other hand, subsidence of the bottom of the inflating sills choked the flow of further buoyant material into the feeder dykes and inhibited the further growth of the two phacoliths. Inflation of the lensoidal intrusives terminated after $c$. 5 min centrifuging when no increase of the bulge on the surface of the model was observed. Until then about 4 to $5 \mathrm{~cm}^{3}$ of the buoyant material had been emplaced into the tabular intrusive bodies, i.e. the buoyant reservoirs had been depleted by 10 to 12.5 vol. \%.

It can be excluded that the formation of both intrusive PDMS bodies through roof uplift and floor depression were influenced by boundary effects such as the relatively small volume of the sample box, because both lensoidal intrusions and their structural aureoles look very much alike irrespective from their relative position within the model and the sample box. Moreover, the total volume of the intrusions is only c. $10 \mathrm{~cm}^{3}$, i.e. less than $2 \%$ of the entire model volume $\left(c .530 \mathrm{~cm}^{3}\right)$.

\section{Implications of the experiment for the emplacement of tabular plutons}

Scaling the model to nature the lensoidal intrusive buoyant bodies would represent $1 \mathrm{~km}$ thick and 3 to $4 \mathrm{~km}$ long granitoid phacoliths (Tabs 1 and 2) that were emplaced at $3.2 \mathrm{~km}$ and $6.05 \mathrm{~km}$ depths, respectively, i.e. at different levels within the upper continental crust.

Both tabular intrusions formed - similar to what is known from their natural counterparts - along anisotropies within the model, i.e. along the interfaces between individual overburden layers. Corresponding anisotropies in nature are horizontal lithological contacts, foliation and fracture planes or shear zones.

The phacolithic shape of the intrusions suggests that space for their emplacement was made by both roof uplift and floor depression, independent of their intrusion depth. This observation contradicts the hypothesis of Cruden (1998) who suggested roof uplift to be only an important space-making process for plutons in the uppermost crust, while floor depression is responsible for the emplacement of all other, deeper-seated tabular plutons. We have to point out that the reason behind achieving roof uplift by the lower intrusion is because of the presence of another weak buoyant layer in the middle of the model stratigraphy. This weak layer enabled and accommodated the roof uplift at deeper level. In other words, in our model, similar to a shallow intrusive body, even the deeper intrusive body uplifted its roof. This was possible because the roof uplift of the deeper intrusion was accommodated by flow of the upper buoyant (viscous) layer. In practice, the mechanical thickness of the overburden units above the lower buoyant layer is relatively thin. The presence of the upper buoyant weak layer enables and accom- 
modates roof uplift by the deeper intrusion. Absence of this shallow buoyant weak horizon would have resulted in a thicker overburden unit, which might not have been uplifted by a deep intrusion. Presence of layered intrusions may assist roof uplift even at deeper levels. The same is in principle true for floor depression which was facilitated by the presence of the two relatively low-viscous PDMS source layers beneath the two developing lensoidal PDMS intrusions.

Plotting the length and thickness data of the PDMS laccolith in the $\log _{\text {length }}$ vs. $\log _{\text {thickness }}$ diagram of Petford et al. (2000) with the regression lines for laccolith and tabular plutons (Fig. 1) the data pairs of both sections of the model appear close to the regression line for laccoliths. The model intrusions are definitely not laccolithic in shape and were, consequently, not only emplaced by roof uplift - as typical of laccoliths (Figs 7-9 and Tab. 1). On the contrary, they are biconvex in shape and were intruded by a combination of roof uplift and floor depression - as it is typical of phacoliths. Obviously, more data from nature and models - in particular reliable thickness data for granitoid bodies - are necessary to improve the regression lines which could then describe better the shape of different types of intrusions.

Displacement of the top and bottom sides of both the experimental tabular intrusions took place plastically. No brittle deformation or concentration of deformation along discrete fractures, faults or shear zones was observed as it might be the case for most natural lacco- lopo- or phacoliths (e.g. Bussel 1976; Dehls et al. 1998; Zimmerman 2005; Hacker et al. 2007).

The most prominent feature within the emplacement scenario of the model is the choking of the influx of buoyant material into the feeder dykes of both the phacoliths due to the floor depression of the inflating intrusive bodies. The source layer of the buoyant material was segmented by the subsiding overburden units and further flow into the intrusive body was inhibited. As such, the scenario presented by Cruden (1998), where the depression of the floor of an inflating tabular pluton will force the magma within its source region towards the conduit(s) of the growing pluton, does not apply to our model. We argue therefore that Cruden's (1998) idea depends on the initial geometry of the feeding magma source; a horizontal magma source, possibly a migmatitic layer within the Earth's crust would face the fate as the PDMS source layers of our model, whereas a magma source with an irregular geometry would most likely behave as Cruden (1998) proposed. Nevertheless, the "strangulation" of the buoyant-material supply in the model did not prevent the formation of the intrusive bodies, but restricted their growth to a volume of 4 to 5 $\mathrm{cm}^{3}$ (reached within c. 5 minutes) and limited the depletion of the buoyant reservoir to $c$. $10 \mathrm{vol}$. \%. Transferring these model observations to nature could mean that the size of tabular plutons and their growth rate are not only controlled by the volume of the reservoir and the rate of magma ascent and the magma's physical properties ( $T, \mu$, $\rho$ ), but also by the shape of the magma source region and, moreover, by the effectiveness of vertical, downward-directed material transfer to create space for the build-up of the pluton. Time of the model phacoliths $\left(\mathrm{t}_{\mathrm{m}}\right)$ is scaled to nature $\left(\mathrm{t}_{\mathrm{n}}\right)$ as follows (Ramberg 1981):

$$
t_{n}=\left(t_{m} \times l_{r} \times \rho_{r} \times g_{r}\right) / \mu_{r}
$$

where $l_{r}$ is the length ratio, $\rho_{r}$ is the density ratio, $g_{r}$ is the gravitational acceleration ratio and $\mu_{r}$ is the viscosity ratio between model and nature (for numbers see Tab. 2).

Even if the model is dynamically not properly scaled, because of the too high viscosity of the buoyant material compared to its overburden, time scaling based on the available numbers (Tab. 2) gives a rough estimate of the time span for the formation of a natural phacolith before its growth is stopped due to choking of the influx of more magma by floor depression.

In the model, it took $c .5$ minutes to form a lensoidal intrusion of 4 to $5 \mathrm{~cm}^{3} 0.7 \mathrm{~cm}$ above the buoyant source layer. Accordingly, in nature a phacolith of 4 to $5 \mathrm{~km}^{3}$, being emplaced $700 \mathrm{~m}$ above its source layer, would have formed within c. 1 Ma. This time span would be sufficient to emplace such small tabular plutons. Assuming a lower and more realistic viscosity of the magma $\left(10^{9}\right.$ to $10^{3} \mathrm{~Pa} \cdot \mathrm{s}$, e.g. Clemens and Petford 1999) than that used in the model $\left(10^{18} \mathrm{~Pa} \cdot \mathrm{s}\right)$ more voluminous tabular intrusive bodies could be built in a greater distance from the magma source layer within the same or even a shorter time. Ascent rates of magma through dykes are in the range of $10^{6}$ to $10^{7}$ metres/year (Delaney and Pollard 1981) and the lateral growth rate of a laccolith is assumed by Corry (1988) to be 200-300 metres/year in maximum. According to other authors (e.g. Scaillet et al. 1995; Hogan and Gilbert 1995; Cruden 1998; Petford and Clemens 2000) the construction of plutons of $10^{2}$ to $10^{4} \mathrm{~km}^{3}$ takes $10^{2}$ to $10^{6}$ years. All these figures for rates of magma ascent through dykes and the formation of lensoidal, tabular plutons are in good agreement with the model results presented here.

In conclusion it can be stated that our model shows that roof uplift and floor depression are viable processes to form tabular plutons, but that floor depression might choke a horizontal and layered magma source, thus narrowing the time span for the build-up of a granitoid lopolith or phacolith.

Acknowledgements. The experiment described here was carried out during an international graduate course about pluton emplacement at Uppsala University in September 
2006 with participants from Germany, Greece, Finland and Sweden. Therefore we would like to thank the students of this class $-Z$. Chemia, M. Dümmler, D. Geis, R. Kraus, T. Kravtsov, T. Laurila, M. Mertineit, R. Nyman, H. Oksanen, E. Piispa, M.D. Tranos, R. Unverricht, J. Woodard, K. Zarins - for building, running and discussing the model with us. Thanks are also due to J.L. Vigneresse and P. Závada for their helpful reviews which greatly improved the manuscript. HAK was funded by the Swedish Research Council. We are grateful to O. Jungmann for improving the figures.

\section{References}

Bussels MA (1976) Fracture control of high-level plutonic contacts in the Coastal Batholith of Peru. Proceed Geol Assoc 87: 237-246

Bronstein IN, Semendjajew KA (1987) Taschenbuch der Mathematik. Teubner, Leipzig, pp 1-840

Clemens JD, Petford N (1999) Granitic melt viscosity and silicic magma dynamics in contrasting tectonic settings. J Geol Soc, London 156: 1057-1060

Corry CE (1988) Laccoliths: Mechanics of Emplacement and Growth. GSA Spec Paper 220, Boulder, Colorado, pp 1-110

CRUDEn AR (1998) On the emplacement of tabular granites. J Geol Soc, London 155: 853-862

Cruden AR, Tobisch OT, Launeau P (1999) Magnetic fabric evidence for conduit-fed emplacement of a tabular intrusion: Dinkey Creek pluton, central Sierra Nevada batholith, California. J Geophys Res 104: 10 511-10 530

Dehls JF, Cruden AR, Vigneresse JL (1998) Fracture control of late Archean pluton emplacement in the northern Slave Province, Canada. J Struct Geol 20: 1145-1154

Delaney PT, Pollard, DD (1981) Deformation of host rocks and flow of magma during growth of minette dikes and breccia bearing intrusions near Ship Rock, New Mexico. USGS Prof Paper 1202, pp 1-61

Dingwell, DB, Hess, KU, Romano, C (2000) Viscosities of granitic (sensu lato) melts: influence of the anorthite component. Amer Miner 85: 1342-1348

Garde AA, Hamilton MA, Chadwick B, Grocott J, McCAFFrey KJW (2002) The Ketilidian orogen of South Greenland: geochronology, tectonics, magmatism and fore-arc accretion during Palaeoproterozoic oblique convergence. Can J Earth Sci 39: 765-793

Grocott J, Garde AA, Chadwick B, Cruden AR, Swager C (1999) Emplacement of rapakivi granite and syenite by floor depression and roof uplift in the Palaeoproterozoic Ketilidian orogen, South Greenland. J Geol Soc, London 156: 15-24

Hacker DB, Petronis MS, Holm DK, Geissman JW (2007) Shallow level emplacement mechanisms of the Miocene
Iron Axis Laccolith Group, Southwest Utah. GSA Rocky Mountain Section Annual Meeting Field Guide, pp 1-49

Hammarstrom JM, Zen E (1986): Aluminium in hornblende: an empirical igneous geobarometer. Amer Miner 71: 1297-1313

HeCHT L, VigneRESSE JL (1999) A multidisciplinary approach combining geochemical, gravity and structural data: implications for pluton emplacement and zonation. In: Castro A, Fernandez C, Vigneresse JL (eds) Understanding Granites: Integrating New and Classical Techniques. Geol Soc London Spec Publ 168: pp 95-110

Hogan JP, Gilbert MC (1995) The A-type Mount Scott Granite sheet: importance of crustal magma traps. J Geophys Res 100: 15 779-15 792

KоYI HA (1991) Mushroom diapirs penetrating into high viscous overburden. Geology 19: 1229-1232

Koyı HA (1997) Analogue modelling; from a qualitative to a quantitative technique, a historical outline. J Petrol Geol 20: 223-238

Koyi HA, Milnes AG, Schmeling H, Talbot CJ, Juhlin C, ZEYen H (1999) Numerical models of ductile rebound of crustal roots beneath mountain belts. Geophys J Int 139: 556-562

McCaffrey KJW, Petford N (1997) Are granitic intrusions scale invariant? J Geol Soc, London 154: 1-4

O’BRIEN P (2000) The fundamental Variscan problem: high-temperature metamorphism at different depths and high-pressure metamorphism at different temperatures. In: Franke W, Haak V, Oncken O, Tanner D (eds) Orogenic Processes: Quantification and Modelling in the Variscan Belt. Geol Soc London Spec Publ 179: 369-386

Petford N, Clemens JD (2000) Granites are not diapiric! Geol Today 16: 180-184

Petford N, Cruden AR, McCaffrey KJW, Vigneresse JL (2000) Granite magma formation, transport and emplacement in the Earth's crust. Nature 408: 669-673

Ramberg, H (1981) Gravity, Deformation and the Earth's crust. $2^{\text {nd }}$ edition. Academic Press, London, pp 1-452

Rosenberg CL, Berger A, Schmid SM (1995) Observations from the floor of a granitoid pluton: inferences on the driving force of final emplacement. Geology 23: 443-446

Scaillet B, Pecher A, Rochette P, Champenois M (1995) The Gangotri granite (Garhwal Himalaya): laccolithic emplacement in an extending collisional belt. J Geophys Res 100: 585-608

WeYermars, R (1997) Principles of Rock Mechanics. Alboran Science Publishing, Amsterdam, pp 1-360

ZiMMERMAN, NM (2005) Host rock fracture analysis: applying the deformation mechanics associated with shallow igneous intrusion to the fracture bridging theory, McKinney Hills Laccolith, Big Bend National Park. Master's thesis, Texas Tech University, Lubbock. Available electronically from http://hdl.handle.net/2346/1286 